\title{
Case Report \\ Vascular Calcification in an Adolescent Treated with Long-Term Peritoneal Dialysis
}

\author{
Mesiha Ekim, ${ }^{1}$ Suat Fitoz, ${ }^{2}$ Z. Birsin Ozcakar, ${ }^{1}$ and Fatos Yalcinkaya ${ }^{1}$ \\ ${ }^{1}$ Department of Pediatric Nephrology, School of Medicine, Ankara University, Ankara, Turkey \\ ${ }^{2}$ Department of Radiodiagnostic, School of Medicine, Ankara University, Ankara, Turkey
}

Correspondence should be addressed to Mesiha Ekim, ekim@medicine.ankara.edu.tr

Received 14 March 2011; Accepted 15 March 2011

Academic Editor: Biagio Raffaele Di Iorio

Copyright ( $) 2011$ Mesiha Ekim et al. This is an open access article distributed under the Creative Commons Attribution License, which permits unrestricted use, distribution, and reproduction in any medium, provided the original work is properly cited.

The reason of high mortality in patients with chronic kidney disease (CKD) is cardiovascular disease and arterial calcification has been accepted as an additive factor on this status. In this report we described vascular and cardiac valvular calcifications in an adolescent on CAPD.

\section{Introduction}

Cardiovascular disease (CVD) is the most common cause of death in adult and pediatric patients with CKD [1]. It was determined that cardiac deaths in children and in young adults in whom end-stage renal disease developed during childhood were approximately 1000 times more frequent than in the general pediatric population [2]. Vascular changes were indicated in pediatric patients with dialysis and also in predialysis CKD stages 2-4 [3-6]. These functional and structural vascular abnormalities and arterial calcifications contribute to high cardiac mortality.

In this report, we described the vascular and cardiac valvular calcifications in an adolescent on CAPD.

\section{Case}

A 17-year-old boy on CAPD with 4 exchanges per day $(1000 \mathrm{~mL} /$ body surface area, 2 times $1.36 \%$ and 2 times $2.27 \%$ glucose solution) for 87 months was admitted to the hospital with severe bone pain and fatigue. Erythropoietin, iron, antihypertensive drugs, calcitriol, and calcium containing phosphate binder had been administrated but the patient was incompatible with his medication. He has been followed by another center for last 2 years unregularly. He was pale and growth retarded. Physical examination revealed tachycardia, tachypnea, hypertension, and edema. Laboratory findings were determined as follows: hemoglobin $5.4 \mathrm{~g} / \mathrm{dL}$, hematocrit $22 \%$, serum urea $382 \mathrm{mg} / \mathrm{dL}$, creatinine $9.8 \mathrm{mg} / \mathrm{dL}$, albumin $3.1 \mathrm{~g} / \mathrm{dL}$, calcium $10.6 \mathrm{mg} / \mathrm{dL}$, inorganic phosphorus $8.6 \mathrm{mg} / \mathrm{dL}$, calcium-phosphorus product $91.1 \mathrm{mg}^{2} / \mathrm{dL}^{2}$, iPTH $589 \mathrm{pg} / \mathrm{mL}$ (normal 9.5-75), and CRP $5.6 \mathrm{mg} / \mathrm{dL}$ (normal 0-0.8). Radiologic examination has been performed owing to severe pain on wrists and ankles. In addition to osteopenic appearance vessel wall calcifications were noticed in the radial, ulnar, posterior tibial, anterior tibial, and iliac arteries on radiography (Figures 1, 2, and 3). Computed tomography revealed calcifications in the mitral valve, coronary artery, aorta, splenic, and iliac arteries (Figure 4).

He was transferred to hemodialysis because of ultrafiltration failure. Medical treatment was rearranged according to his clinical and laboratory findings. Calcium containing phosphate binder was changed to calcium-free phosphate binders. His complains subsided and serum phosphorous level decreased gradually.

\section{Discussion}

It was reported that cardiovascular mortality rate is high in pediatric dialysis patients and young adult patients with childhood onset CKD [1]. Calcifications in vascular bed including coronary arteries and cardiac valves are significant risk factors for cardiovascular disease. Milliner et al. [7] retrospectively evaluated biochemical and autopsy data of 


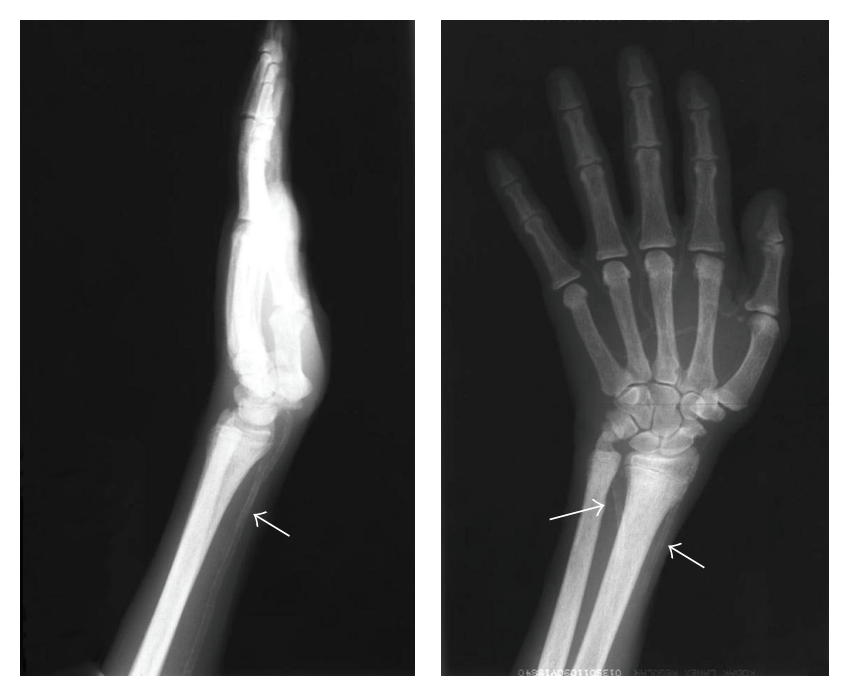

FIGURE 1: Radiographies of right hand reveal calcification of radial and ulnar (arrows) arteries and their distal branches.

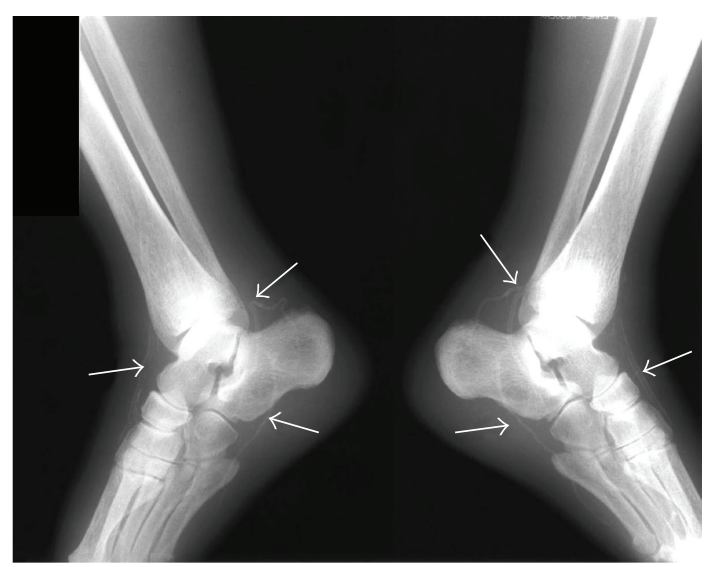

FIGURE 2: Ankle radiographies show anterior and posterior tibial arterial wall calcifications (arrows).

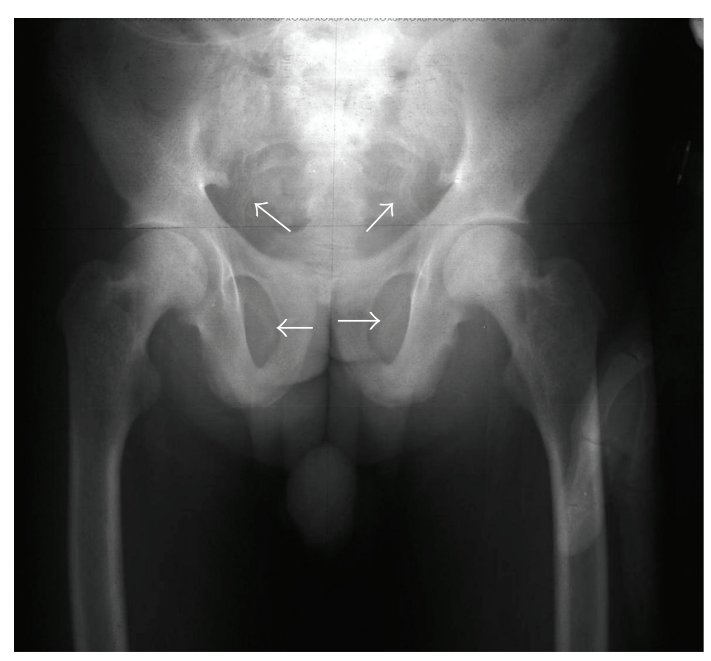

FIGURE 3: Calcification of iliac arteries (arrows) is seen on pelvic radiography. 

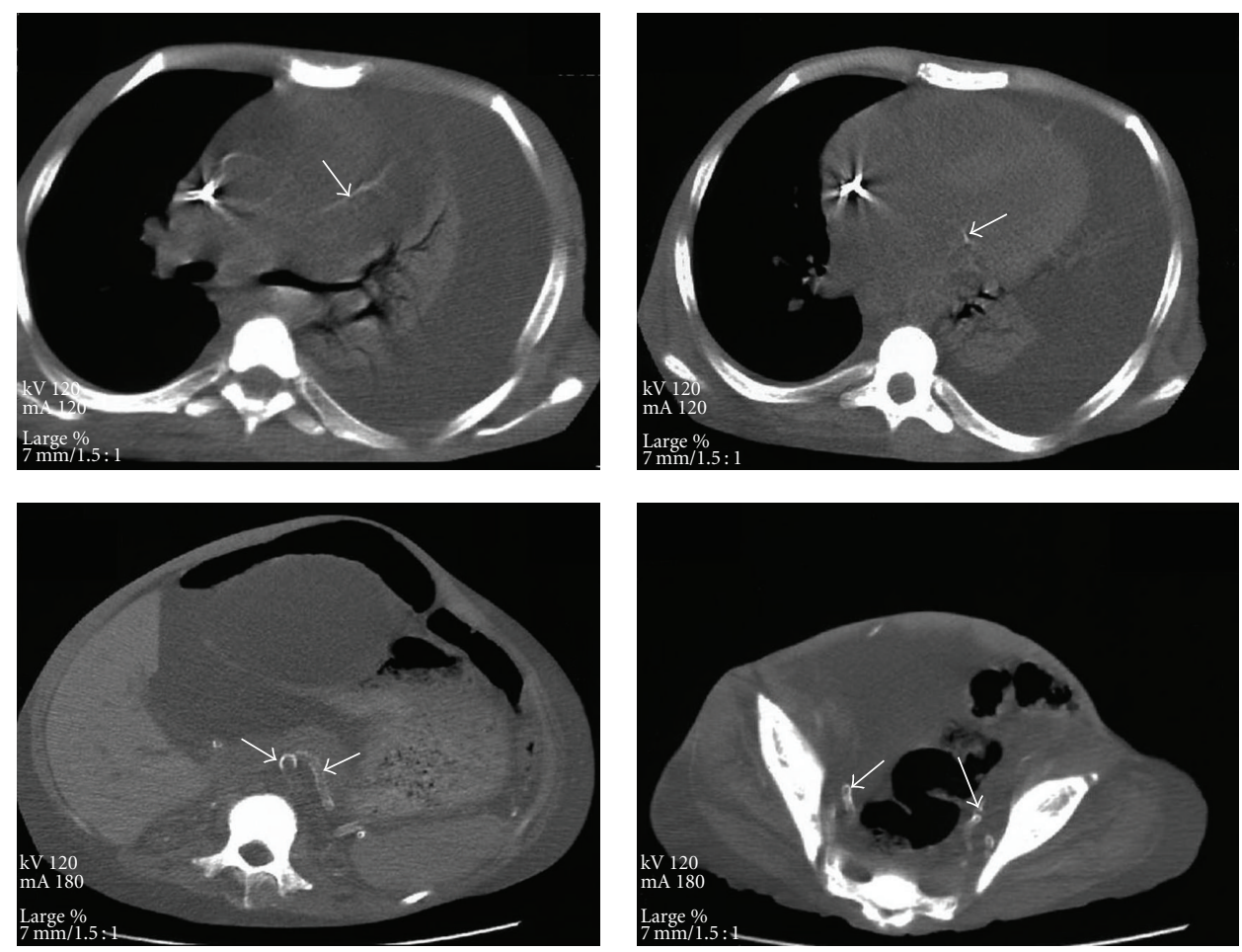

FIgure 4: Axial CT sections from different levels show coronary artery, aorta, splenic, and iliac artery (arrows) calcifications. Also note pleural effusion, ascites, and left lung collapes.

120 pediatric patients with uremia, on dialysis or following renal transplantation in 1990 . They found soft tissue calcification in 72 of 120 patients (60\%) and lung, myocardium, and coronary arteries were frequent sites of calcium deposition. Goodman et al. [8] suggested that calcification is not present before the age of 20 years; however coronary artery calcification (CAC) was detected in pediatric dialysis patients and childhood onset chronic renal failure patients in subsequent studies [9-12]. These vascular changes begin as early as the first decade of life in children on dialysis and are also present in CKD stages 2-4 [3-6].

Prevalence of CAC was reported as $15 \%-20 \%$ in children $[6,12]$. In young adults with childhood-onset chronic renal failure, CAC was found 92\% [10].

Administration of large doses of vitamin D and calcium containing phosphate binders, hypercalcemia, hyperphosphatemia, elevated calcium $\times$ phosphorus $(\mathrm{Ca} \times \mathrm{P})$ product, parathyroid hormone, and duration of dialysis were found to be associated with extraosseous calcifications $[3,6,8,12,13]$.

Plain radiography is the simplest method for the diagnosis of calcification, and a simple scoring system was developed for vascular calcification $[14,15]$. Calcified plaques and cardiac valves can be detected by ultrasonography and echocardiography. Both detection and quantification of calcification can be possible by using computed tomography (CT), especially electron-beam CT [14]. The currently available clinical measurements such as carotis Intima Media Thickness and Pulse Wave Velocity were not sensitive enough to detect early calcium loading [16].
In conclusion, because of high mortality risk, the patients with vascular calcification should be followed carefully in view of cardiovascular diseases. Better dialysis techniques, better patient education about diet and phosphate binders, avoidance of marked or prolonged positive calcium balance, and calibrating the use of vitamin D are important to prevent vascular calcification development.

\section{References}

[1] M. M. Mitsnefes, "Cardiovascular mordibity and mortality in children with chronic kidney disease in North America: lessons from the USRDS and NAPRTCS databases," Peritoneal Dialysis International, vol. 25, no. 3, pp. S120-S122, 2005.

[2] R. S. Parekh, C. E. Carroll, R. A. Wolfe, and F. K. Port, "Cardiovascular mortality in children and young adults with end-stage kidney disease," Journal of Pediatrics, vol. 141, no. 2, pp. 191-197, 2002.

[3] M. Litwin, E. Wühl, C. Jourdan et al., "Altered morphologic properties of large arteries in children with chronic renal failure and after renal transplantation," Journal of the American Society of Nephrology, vol. 16, no. 5, pp. 1494-1500, 2005.

[4] M. Civilibal, S. Caliskan, H. Oflaz et al., "Traditional and "new" cardiovascular risk markers and factors in pediatric dialysis patients," Pediatric Nephrology, vol. 22, no. 7, pp. 1021-1029, 2007.

[5] M. M. Mitsnefes, T. R. Kimball, J. Kartal et al., "Cardiac and vascular adaptation in pediatric patients with chronic kidney disease: role of calcium-phosphorus metabolism," Journal of 
the American Society of Nephrology, vol. 16, no. 9, pp. 27962803, 2005.

[6] R. C. Shroff, A. E. Donald, M. P. Hiorns et al., "Mineral metabolism and vascular damage in children on dialysis," Journal of the American Society of Nephrology, vol. 18, no. 11, pp. 2996-3003, 2007.

[7] D. S. Milliner, A. R. Zinsmeister, E. Lieberman, and B. Landing, "Soft tissue calcification in pediatric patients with end-stage renal disease," Kidney International, vol. 38, no. 5, pp. 931-936, 1990.

[8] W. G. Goodman, J. Goldin, B. D. Kuizon et al., "Coronaryartery calcification in young adults with end-stage renal disease who are undergoing dialysis," The New England Journal of Medicine, vol. 342, no. 20, pp. 1478-1483, 2000.

[9] F. Eifinger, F. Wahn, U. Querfeld et al., "Coronary artery calcifications in children and young adults treated with renal replacement therapy," Nephrology Dialysis Transplantation, vol. 15, no. 11, pp. 1892-1894, 2000.

[10] J. Oh, R. Wunsch, M. Turzer et al., "Advanced coronary and carotid arteriopathy in young adults with childhood-onset chronic renal failure," Circulation, vol. 106, no. 1, pp. 100-105, 2002.

[11] R. D. Sheth, M. D. Perez, and S. L. Goldstein, "Cardiovascular calcifications in pediatric patients receiving maintenance dialysis," Pediatric Nephrology, vol. 18, no. 8, pp. 810-813, 2003.

[12] M. Civilibal, S. Caliskan, I. Adaletli et al., "Coronary artery calcifications in children with end-stage renal disease," Pediatric Nephrology, vol. 21, no. 10, pp. 1426-1433, 2006.

[13] G. A. Block, T. E. Hulbert-Shearon, N. W. Levin, and F. K. Port, "Association of serum phosphorus and calcium x phosphate product with mortality risk in chronic hemodialysis patients: a national study," American Journal of Kidney Diseases, vol. 31, no. 4, pp. 607-617, 1998.

[14] D. Goldsmith, E. Ritz, and A. Covic, "Vascular calcification: a stiff challenge for the nephrologist-does preventing bone disease cause arterial disease?" Kidney International, vol. 66, no. 4, pp. 1315-1333, 2004.

[15] T. Adragao, A. Pires, C. Lucas et al., "A simple vascular calcification score predicts cardiovascular risk in haemodialysis patients," Nephrology Dialysis Transplantation, vol. 19, no. 6, pp. 1480-1488, 2004.

[16] R. Shroff, "Monitoring cardiovascular risk factors in children on dialysis," Peritoneal Dialysis International, vol. 29, no. 2, pp. S173-S175, 2009. 


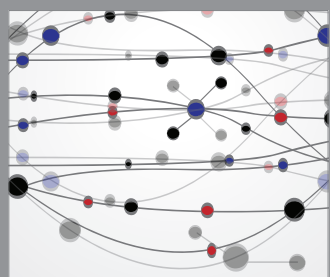

The Scientific World Journal
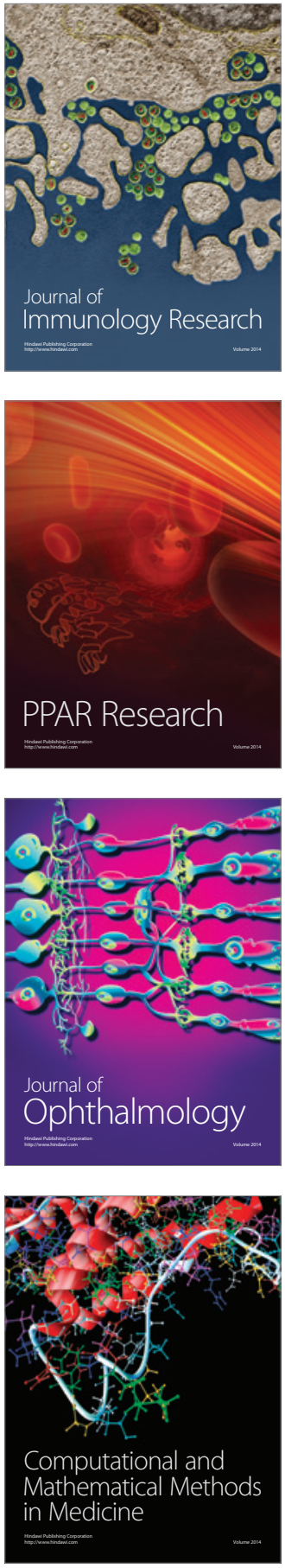

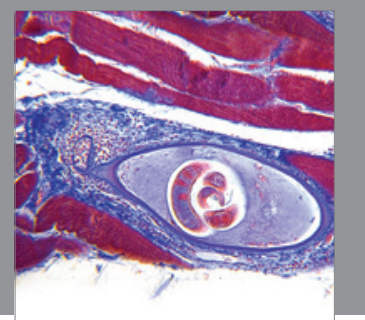

Gastroenterology

Research and Practice
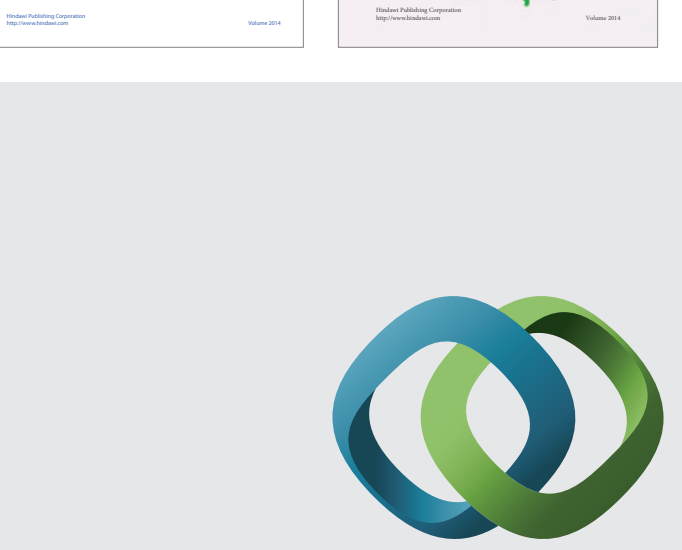

\section{Hindawi}

Submit your manuscripts at

http://www.hindawi.com
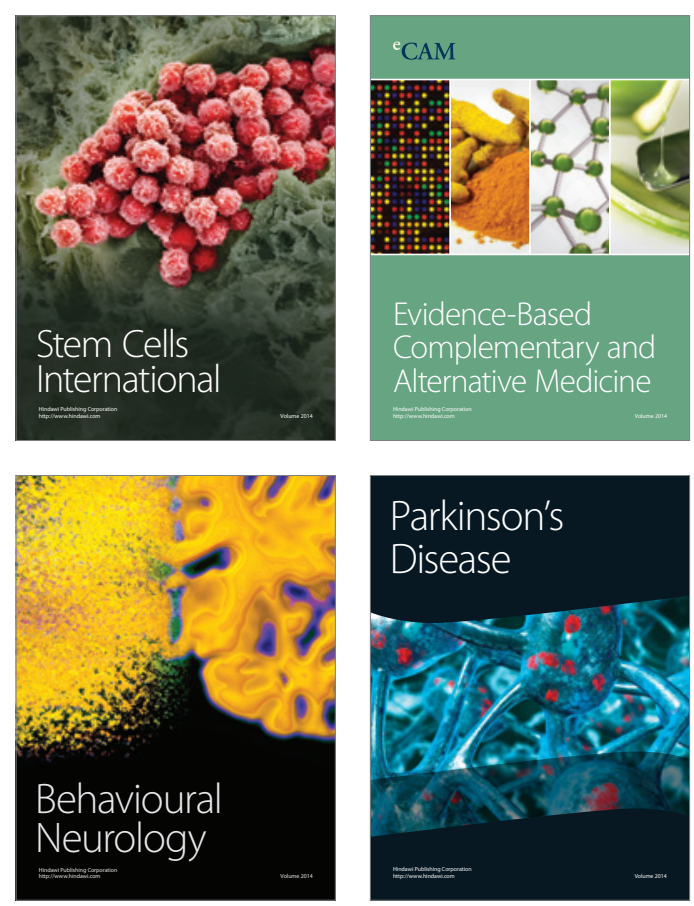

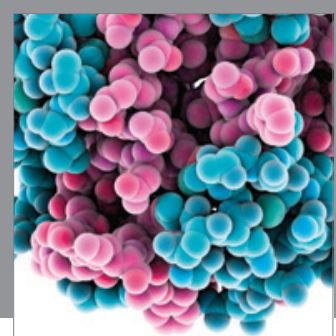

Journal of
Diabetes Research

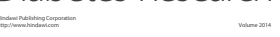

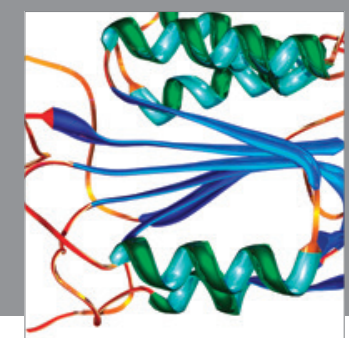

Disease Markers
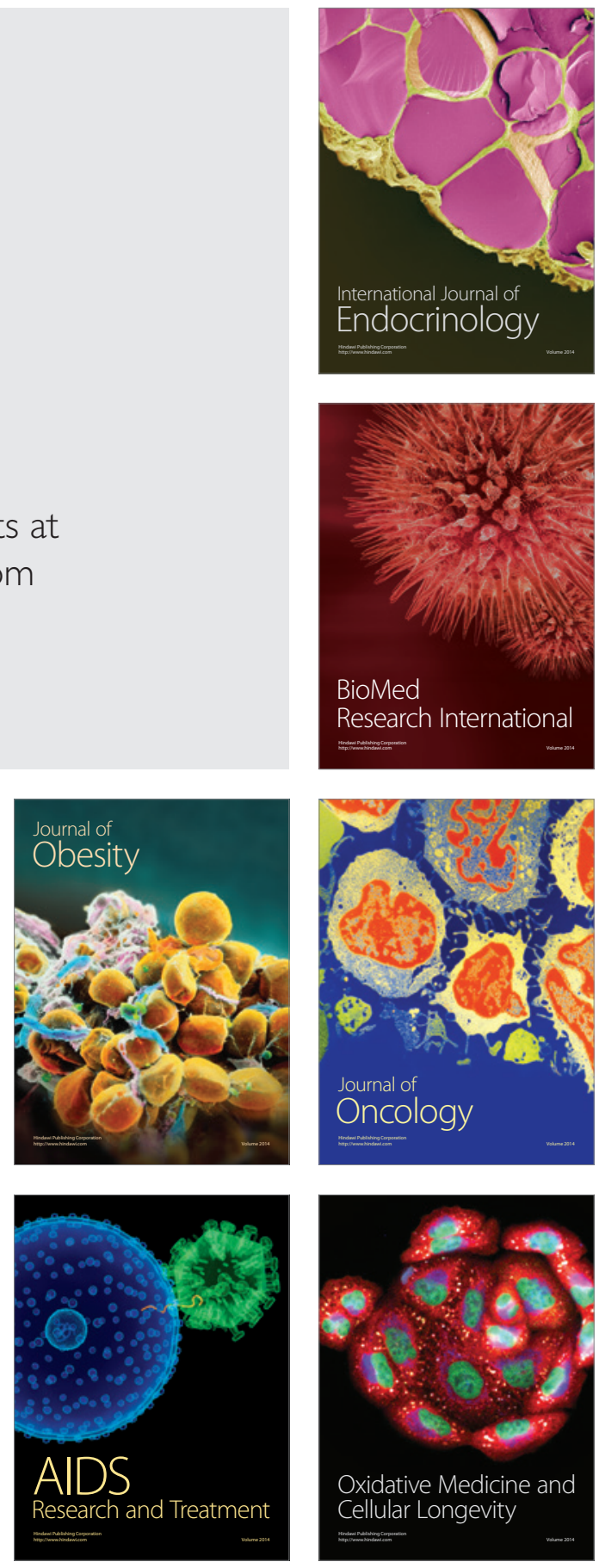